Reviews in Digital Humanities • Vol. 2, No. 5

\title{
Review: Mapping Marronage
}

\author{
Shavagne $S \operatorname{cott}^{\mathbf{1}}$ \\ ${ }^{1_{N}}$ ew York University
}

Published on: May 10, 2021

DOI: $10.21428 / 3 e 88 f 64 f . b f 990101$

License: Creative Commons Attribution 4.0 International License (CC-BY 4.0). 


\section{Project}

Mapping Marronage

\section{Project Director}

Annette Joseph-Gabriel, University of Michigan

\section{Project URL}

http://mapping-marronage.rll.lsa.umich.edu/

\section{Project Reviewer}

Shavagne Scott, New York University

\section{Project Overview}

\section{Annette Joseph-Gabriel}

Mapping Marronage is an interactive visualization of the trans-Atlantic movement of enslaved people in the 18th and 19th centuries. Marronage, as conceptualized in this project, is not limited to its oft-evoked definition of flight from the plantation to the mountains or swamps. Instead, drawing on broader notions of flight as attempts to move individuals beyond capture and create communities beyond the confines of enslavement, this project engages with marronage writ large. Its point of departure, therefore, is a capacious definition of marronage that considers the different forms of flight by which enslaved people sought to move - with varying degrees of success beyond slavery's reach. Consequently, this digital map traces the geographic reach, crossings, and intersections of people, letters, autobiographies, and creative works that attest to the liberatory possibilities of mobility for people of African-descent in the Atlantic world.

Mapping Marronage was built in Drupal and runs on the Creative Commons-licensed code that powers an existing network map, In the Same Boats. Mapping Marronage was awarded an American Philosophical Society Digital Humanities Fellowship, as well as a University of Michigan New Initiatives/New Infrastructure grant, which constitutes its primary source of funding. The project team consists of three groups of contributors:

1. The principal investigator, Annette Joseph-Gabriel, is responsible for the project's vision, framing, and the humanistic questions the project seeks to explore about the nature and implications of mobility for enslaved people in the Atlantic world; 
2. Software developers at Agile Humanities built the site and maintenance is currently undertaken by staff at the University of Michigan Language Resource Center; and

3. Student researchers in Joseph-Gabriel's Mapping the French Atlantic course contributed much of the data that constitutes the map's contents.

Mapping Marronage offers different possibilities for users. As a resource for research, the visualization presents information on the overlaps and intersections in the lives, movement, and work of different enslaved people who may not initially appear to be connected. The site also provides curated access to archival material and allows users to consult and engage with a variety of primary documents from archives around the world. These documents include letters, inventories, manumission papers, and testimonies that highlight the role of movement in claiming freedom in the Atlantic world. As a teaching tool, Mapping Marronage allows students to engage in hands-on collaboration that bridges the gap between often-solitary archival work and collaborative project work. The site also allows students involved in the project to think through effective ways of engaging new audiences in historical study. Students have done so by creating a lesson plan bank for use at the middle and high school level.

The project team is currently discussing collaboration possibilities with the New Orleans Jazz Museum, Ranson IB Middle School in Charlotte, North Carolina, and Create Caribbean in Dominica. Joseph-Gabriel will also work with high school student interns from the Ann Arbor and Ypsilanti area as part of the Wolverine Pathways college preparation program. These collaborations will primarily involve working with students on consulting archives, translation, transcription, and data mining.

\section{Project Review}

\section{Shavagne Scott}

Mapping Marronage is an interactive project that tracks the material correspondences and exchanges of 18th and 19th century enslaved people of African descent. The project eschews the dominant narrative of marronage as a process of flight to isolated regions, in line with recent historical scholarship on the topic. It does so to bring attention to the different forms that flight and movement took during trans-Atlantic slavery. Critically, marronage in this project, as the "About" page describes, represents, "Any act by which an enslaved person seeks to move him/herself beyond the reach of slaveholders' power." With this broad view of marronage, the project is able to visually 
highlight the movement and intersections of the letters, testimonies, and financial exchanges of enslaved people. Users leave with the understanding that marronage was both a concrete process of removal and a state of being.

The core interactive features of the project include a section that tracks the enslaved persons themselves ("Flight") and another that traces correspondences ("Networks"). An easy to use interface built by Agile Humanities, based on the codebase for Kaiama L. Glover and Alex Gil's In the Same Boats, permits a seamless process of navigation for users. The "Flight" section includes tooltips with detailed biographies and links to archival sources that pinpoint an individual's movements. An interactive map further locates the enslaved person's geographic points of entanglement with the receivers of their correspondences and with others whose lives intersected with theirs spatially and temporally. The "Network" section has similar interactive layouts as the "Flight" section, but it focuses on networks that an enslaved person formed through their exchanges. Both sections include interactive timelines that allow users to control date ranges. Users can also use the timeline to connect the experiences and movements of individuals who might otherwise seem unconnected.

Focusing on the material basis of enslaved people's movements allows for two things. First, it shows how both coercive and voluntary factors informed the broad geographic movements and points of entanglement of enslaved people of African descent. Second, it offers a visual way to transcend the emphasis on masculinity that traditional archives on trans-Atlantic mobility privilege. Court cases, for instance, bring women to the forefront, given their use of the legal realm in areas such as the French Atlantic. With more additions to the database, which currently includes 16 individuals, five of whom are women, enslaved women's movement and the networks they created will be further highlighted.

As the project grows, additional features could be added to improve usability and accessibility. For example, a search bar that integrates themes, years, and points of origins would make the site more accessible to K-12 teachers and students. Moreover, Agile's Drupal-based design could allow the site to include translated archival documents alongside their original versions. This particular addition would enhance a project already well on its way to countering the dominance of the British-Atlantic, given the area of expertise of the creator, Annette Joseph-Gabriel, and the French Atlantic connections already included in the database. The inclusion of other Atlantic regions would help map marronage more fully. 
